\title{
Corrosion Evaluation of Steel Rebar Using Electromagnetic Induction Method
}

\author{
Dongfeng $\mathrm{HE}^{1}$ \\ National Institute for Materials Science, Sengen 1-2-1, Tsukuba, Japan
}

\begin{abstract}
Corrosion of steel reinforcing bar (rebar) reduces the strength capacity of concrete, and also causes the crack of concrete due the volume increase of the corrosion products. Detection of corrosion at its early stage is important for the safety evaluation and repairment of the concrete structures. An electromagnetic induction method was developed to evaluate the corrosion of steel rebar. By measuring the electromagnetic response of steel rebar, it was possible to judge the corrosion of steel rebar in concrete. A small compact system, suitable for field experiments was also developed.
\end{abstract}

Keywords. Steel rebar, corrosion, electromagnetic method.

\section{Introduction}

Steel reinforcing bar (Rebar) is often used in concrete structure to increase the strength capacity. In case of fresh uncracked concrete, the concrete covering over the rebar is very effective in inhibiting the penetration of corrosive agents to the steel. Also, fresh concrete has a high $\mathrm{pH}$ (a unit to measure the acidity of a substance) value which usually inhibits corrosion reactions. However, as time passes the above conditions tend to alter. Water, salt, $\mathrm{O}_{2}, \mathrm{CO}_{2}$, and industrial gases (if present) slowly begin penetrating the concrete, both the $\mathrm{pH}$ value and the protective quality of concrete are decreased. For the concrete used in severe environments where sea water or deicing salts are present. When chloride moves into the concrete, it disrupts the passive layer protecting the steel, causing it to rust and pit. Carbonation of concrete is another cause of steel corrosion. When concrete carbonates to the steel rebar, the normally alkaline environment, protesting steel rebar from corrosion, is replaced by a more neutral environment. Occasionally, a lack of oxygen surrounding the steel rear will cause the metal to dissolve, leaving a low $\mathrm{pH}$ liquid. Figure 1 shows the corrosion progress of steel rebar in the service period of concrete structures and the maintenance. In the incubation period, the steel rebar is protected by the oxidic layer of the steel rebar and the high $\mathrm{pH}$ value environment in the concrete. Then, after several years, the inner environment of the concrete is altered and the $\mathrm{pH}$ value is reduced. The corrosion of steel rebar starts and causes the crack of the concrete due to the volume increase of the corrosion products. Then, water can easily penetrate to the steel rebar through the crack, that accelerates the corrosion of steel rebar. The periodic inspection of the steel rebar in concrete is necessary and important for safety management. Knowing the conditions of

\footnotetext{
${ }^{1}$ Corresponding Author, Dongfeng He, Research Centre of Structural Materials, National Institute for Materials Science, Sengen 1-2-1, Tsukuba, Ibaraki 305-0047; E-mail: he.dongfeng@nims.go.jp.
} 
the steel rebar, such as the location, the diameter, and the corrosion of steel rebar, is important for the safety evaluation of concrete structures.

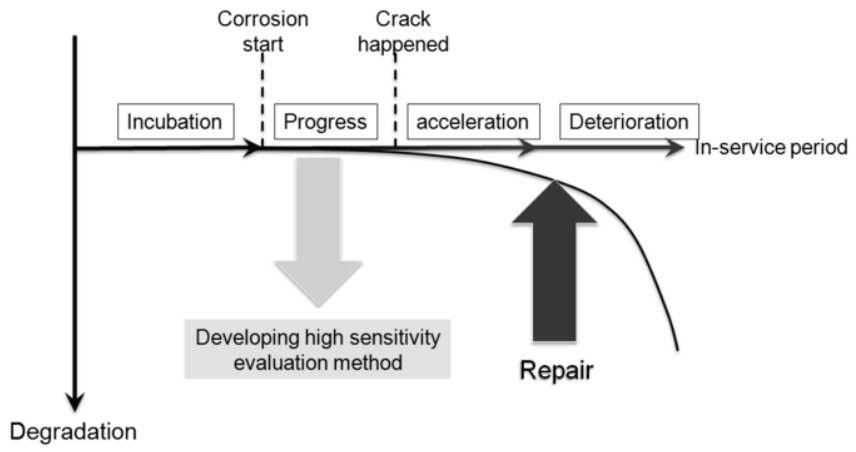

Figure 1. Corrosion progress of steel rebar in concrete and the maintenance of concrete structure.

Electrochemical potential and impedance methods [1,2] are often used to monitor the corrosion of steel rebar in concrete. But it is difficult to locate the corrosion position using these methods. In recent years, ultrasonic waves [3,4] are used for early detection and assessment of localized damage in bare rebars in the form of corrosion pits. Electromagnetic induction (AC field) method [5-9], Microwave radar system [1012], thermography technology [13, 14], and X-ray method [15] have also been used to evaluate the corrosion of the steel rebar in concrete. For the microwave radar systems, the water or moisture in the concrete structures may have big influence to the detection accuracy. For the X-ray method, the transmitter and the receiver are often on the opposite side. It is not convenient to do field experiments. Pulsed eddy current (PEC) thermography is used to get the image of the steel rebar corrosion. Due to the thermal insulation of the concrete, it is difficult to detect the corrosion of steel rebar with the large depth. Compared with other methods, the low frequency electromagnetic induction method has the advantages of low cost, easy operation, and less moisture influence. In this paper, we will report our experiments of corrosion evaluation of steel rebar using electromagnetic induction evaluation system.

\section{Principle of electromagnetic induction method}

Table I shows several kinds of corrosion products and their permeabilities and electrical conductivities. The electrical conductivities of all the corrosion products are smaller than that of carbon steel (steel rebar). The permeabilities of $\mathrm{FeO}$ and $\mathrm{FeOOH}$ are smaller than that of steel rebar, and the permeabilities of $\mathrm{Fe}_{2} \mathrm{O}_{3}$ and $\mathrm{Fe}_{3} \mathrm{O}_{4}$ are bigger than that of steel rebar.

Table I. Corrosion products and their permeabilities and conductivities.

\begin{tabular}{|l|l|l|}
\hline & Relative permeability & Electrical conductivity (S/cm) \\
\hline Carbon steel (steel rebar) & 100 & $7 \times 10^{4}$ \\
\hline $\mathrm{FeO}$ & 1.0072 & 300 \\
\hline $\mathrm{FeOOH}$ & 1.1 & $5 \times 10^{-9}$ \\
\hline $\mathrm{Fe}_{2} \mathrm{O}_{3}$ & Hundreds & $10^{-4}$ \\
\hline $\mathrm{Fe}_{3} \mathrm{O}_{4}$ & Hundreds & 200 \\
\hline
\end{tabular}


The corrosion layer of the steel rebar is often composed of the mixture of above corrosion products. Compared with the steel rebar without corrosion, the corrosion layer has different electrical conductivity and permeability, so it also has different responses to the applied electromagnetic field

Figure 2 shows the principle of low frequency electromagnetic induction method to evaluate the corrosion of steel rebar. The big excitation coil is used to produce the AC magnetic field when AC current flows in the excitation. The small detection coil is used to measure the magnetic field produced by the steel rebar. The lock-in amplifier was used to get the $\mathrm{X}$ and $\mathrm{Y}$ signal, where the $\mathrm{X}$ signal was the same phase signal with the excitation magnetic field, and the $\mathrm{Y}$ signal was the signal with 90-degree phase difference with the excitation magnetic field.

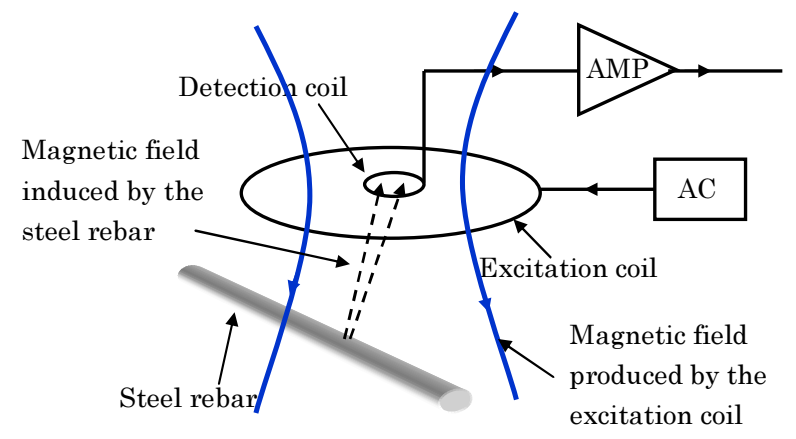

Figure 2. Principle of electromagnetic method to evaluate the corrosion of steel rebar.

There are two effects existing for the steel rebar: magnetization effect and eddy current effect. At very low frequency, the magnetization effect determines the signal; at high frequency, the eddy current effect determines the signal.

\section{Experimental system and experimental results}

We developed a compact experimental system. Figure 3 shows it. The excitation coil, the detection coil, the amplifier, the lock-in amplifier and the AD converter all were put in a small box of about $9 \mathrm{~cm} \times 12 \mathrm{~cm} \times 7 \mathrm{~cm}$. Only one USB cable connected with a computer was used for the data transferring and the power supplying. The total power consumption of the system was about $0.5 \mathrm{~W}$. Labview program was developed for data acquisition and data procession. In our experiments, the frequency was about $80 \mathrm{kHz}$, the diameter of the excitation coil was $3 \mathrm{~cm}$ with 100 turns, and the detection coil was $1 \mathrm{~cm}$ with 100 turns. When big excitation coil was used, big detection depth could be achieved, but the neighboring steel rebar might also have big influence. The corrosion of the steel rebar normally happens with the depth smaller than $5 \mathrm{~cm}$. Therefore, $3 \mathrm{~cm}$ excitation was used in our system. When the excitation frequency was low, the signal difference was small for different corrosion level; when the frequency was high, the stability of the system became less, so the excitation frequency of $80 \mathrm{kHz}$ was chosen according to our experiments. 


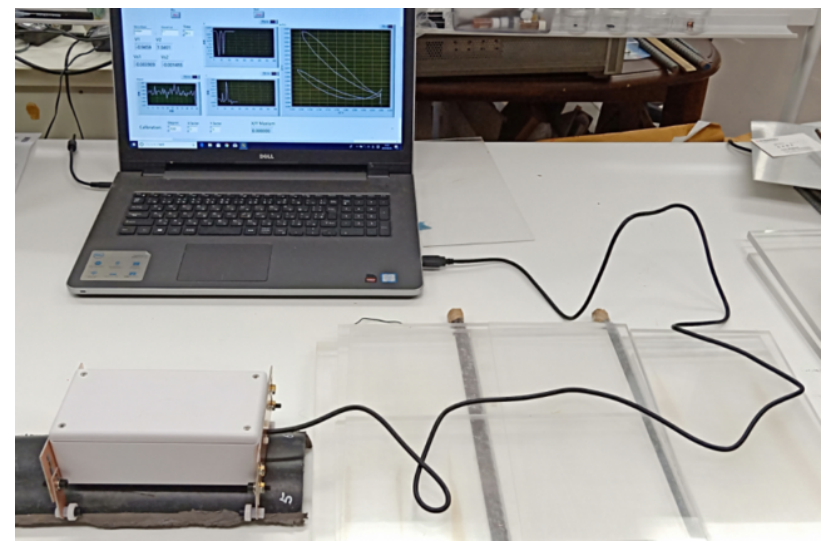

Figure 3. Compact electromagnetic system for the corrosion evaluation of steel rebar.

Figure 4 shows the samples of steel rebar with different corrosion levels. The samples were the deformed steel rebars with the diameter of $16 \mathrm{~mm}$. The steel rebar "a" had no corrosion; steel rebar " $b$ " had a little corrosion, there were some corroded dots on the surface the steel rebar; steel rebar "c" had big corrosion, the thickness of the corroded layer was about $0.1 \mathrm{~mm}$ and steel rebar " $d$ " had severe corrosion with the thickness of the corrosion layer of about $1 \mathrm{~mm}$. The steel rebars were from concrete structures, not prepared by artificial corrosion. The corrosion layer was normally the mixture of several kinds of corrosion products.

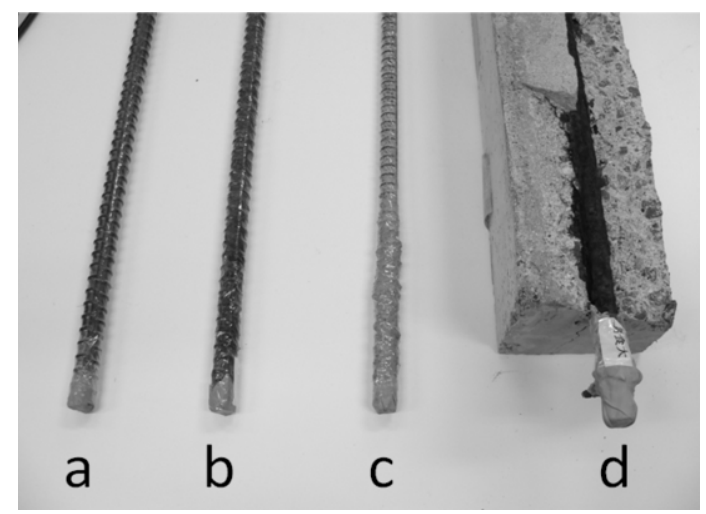

Figure 4. Samples of steel rebar. a: no corrosion. b: a little corrosion with corroded dots on the surface. c: big corrosion with the $0.1 \mathrm{~mm}$ corroded layer. $\mathrm{d}$ : severe corrosion with $1 \mathrm{~mm}$ corroded layer.

We scanned the samples of the steel rebars using the electromagnetic system. The samples were covered by concrete plates with different thicknesses. When $3 \mathrm{~cm}$ excitation coil was used, the maximum detection depth was about $7 \mathrm{~cm}$. Figure 5 shows the $X-Y$ graphs of the signals when the covering depth was $2 \mathrm{~cm}, 3 \mathrm{~cm}, 4 \mathrm{~cm}$, and $5 \mathrm{~cm}$ respectively. The $\mathrm{X}-\mathrm{Y}$ graphs were plotted using the $\mathrm{X}$ and $\mathrm{Y}$ output signals of the lock-in amplifier. The slopes were different for the steel rebars with different corrosion levels. For the same steel rebar sample, the slopes were similar for different covering depths. 

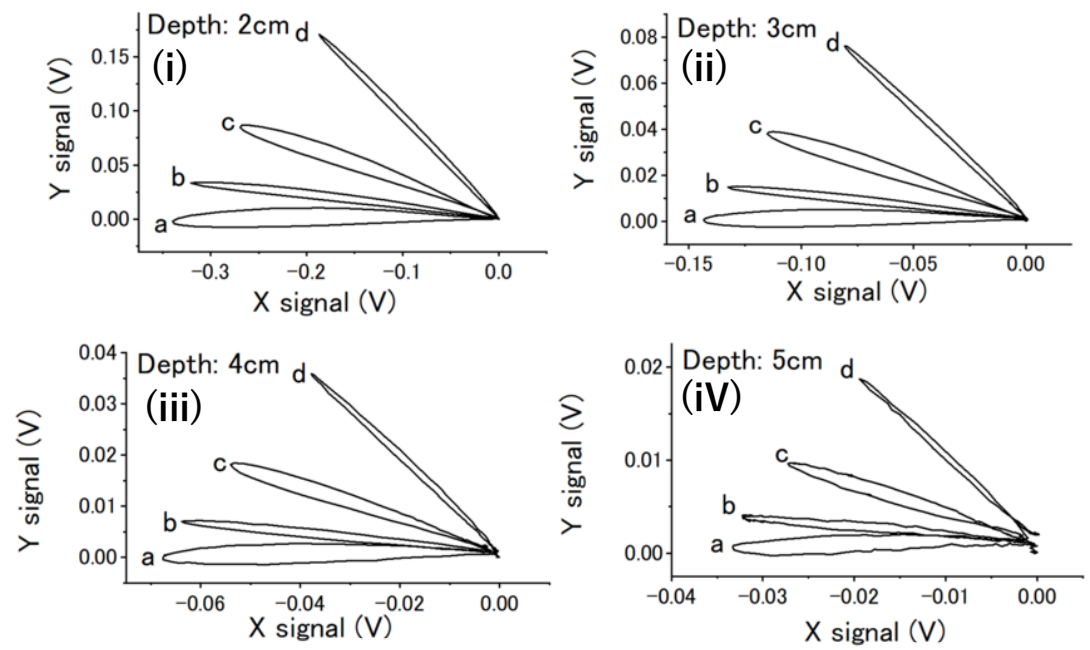

Figure 5. X-Y graphs of the signals when the covering depth was $2 \mathrm{~cm}, 3 \mathrm{~cm}, 4 \mathrm{~cm}$, and $5 \mathrm{~cm}$ respectively.

We measured the influences of neighbor steel rebar and found that the influence was small when the distance of two steel rebar was bigger than $10 \mathrm{~cm}$. We also measured the influence of the cross steel rabar. Figure 6 shows it. Two steel rebars were put on the top: one had corrosion and another had no corrosion. The other two steel rebars without corrosion were put on the bottom. The steel rebars were covered by the acrylic plate with thickness of $4 \mathrm{~cm}$. In Figure 6(a), the scanning direction was in the middle of the bottom two steel rebars. In Figure 6 (b), the scanning was over one of the bottom steel rebar. Figure 6(c) and Figure 6(d) shows the results respectively. The differences could be observed for the steel rebars with corrosion and without corrosion. The signals were reset to zero as the probe was put on the acrylic plate before the scanning. For the two cases, the bottom steel rebars had less influence to the slopes of the signals.
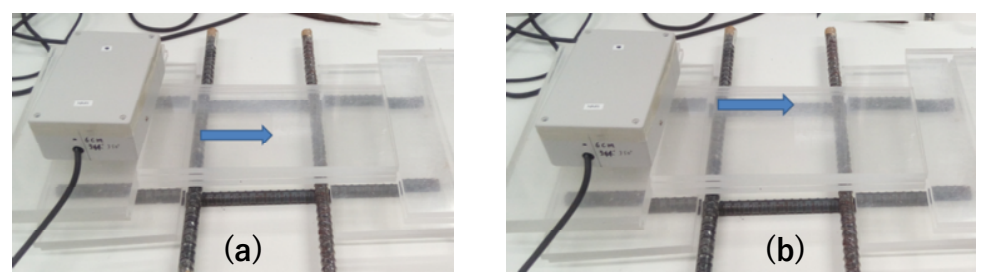

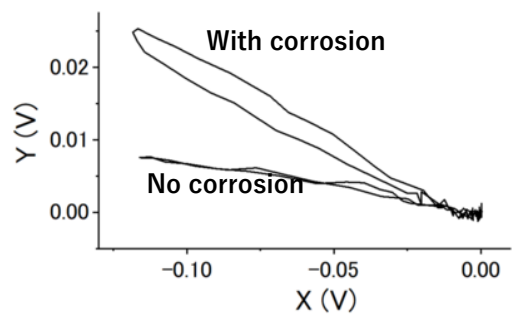

(c)

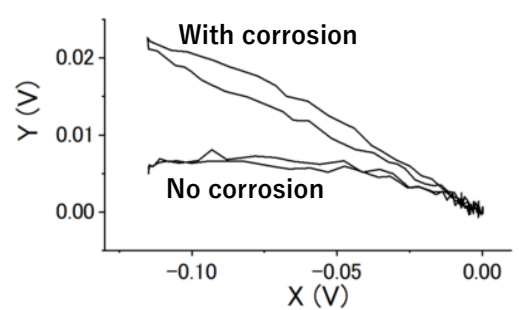

(d)

Figure 6. Measuring the influence of cross steel rebar. 


\section{Summary}

We developed electromagnetic induction methods to evaluate the corrosion of steel rebar. Using the frequency about $80 \mathrm{kHz}$ and the $\mathrm{X}, \mathrm{Y}$ output signals of the lock-in amplifier, the corrosion of steel rebar was evaluated using the slope of the X-Y graph. The slope was determined by the material of the steel rebar and the corrosion level of steel rebar. It had less relation with the depth or distance from the steel rebar. In the future, simulation will be used to optimize the probe.

\section{Acknowledgment}

This work was supported by Council for Science, Technology and Innovation, "Crossministerial Strategic Innovation Promotion Program (SIP), Infrastructure Maintenance, Renovation, and Management”, (JST Funding: No. JST-SIP-K07).

\section{References}

[1] R. Ravi, G.T. Parthiban, "Potential monitoring system for corrosion of steel in concrete," Advances in Engineering Software, 37 (2006), 375-381

[2] Yoshinao Hoshi, Taisuke Koike, Hiroyuki Tokieda, Isao Shitanda, Masayuki Itagaki, Yoshitaka Kato, "Non-contact measurement to detect steel rebar corrosion in reinforced concrete by electrochemical impedance spectroscopy," Journal of the Electrochemical Society, 166 (2019), C3316-C3319.

[3] Rajeshwara Chary Sriramadasuabc, Sauvik Banerjeeb, Ye Lu, "Detection and assessment of pitting corrosion in rebars using scattering of ultrasonic guided waves," NDT \& E International, 101 (2019), 53-61

[4] Peng Du, DongyuXu, Shifeng Huang, Xin Cheng, "Assessment of corrosion of reinforcing steel bars in concrete using embedded piezoelectric transducers based on ultrasonic wave," Construction and Building Materials, 151 (2017), 925-930.

[5] P.A. Gaydecki, F.M. Burdekin, "An inductive scanning system for two dimensional imaging of reinforcing components in concrete structures," Meas. Sci. Techno., 5 (1994), 1272-1280.

[6] Z.Z. Yu, P.A. Gaydecki PA, I. Silva I, B.T. Fernandes, F.M. Burdekin, "Magnetic field imaging of steel reinforcing bars in concrete using portable scanning systems," Review of Progress in Quantitative Nondestructive Evaluation, 18 (1999), 2145-2152.

[7] P. Gaydecki, I. Silva, B.T. Fernandes, Z.Z. Yu, "A portable inductive scanning system for imaging steel-reinforcing bars embedded within concrete," Sensors and Actuators A, Physical, 84 (2000), 25-32.

[8] G. Miller, P. Gaydecki, S. Quek, B. Fernandes, and M. Zaid, "A combined Q and heterodyne sensor incorporating real-time DSP for reinforcement imaging, corrosion detection and material characterization," Sensors and Actuators A, Physical, 121 (2005), 339-346.

[9] G. Miller, P. Gaydecki, S. Quek, B.T. Fernandes, M.A.M. Zaid, "Detection and imaging of surface corrosion on steel reinforcing bars using a phase-sensitive inductive sensor intended for use with concrete," NDT\&E International, 36 (2003), 19-26.

[10] J.H. Bungey, and S.G. Millard, "Radar inspection of structures," Proceedings of the Institution of Civil Engineers - Structures and Buildings, 99 (1993), 173-178.

[11] T.C.K. Molyneaux, S.G. Millard, J.H. Bungey, and J.Q. Zhou, "Radar assessment of structural concrete using neural networks," NDT\&E International, 28 (1995) 281-288.

[12] M.R. Shaw, S.G. Millard, T.C.K. Molyneaux, M.J. Taylor, J.H. Bungey, "Location of steel reinforcement in concrete using ground penetrating radar and neural networks," NDT\&E International, 38 (2005), 203-212.

[13] S.A. Keo, F. Brachelet, F. Breaban, D. Defer, "Steel detection in reinforced concrete wall by microwave infrared thermography," NDT\&E International, 62 (2014), 172-177.

[14] Yunze He, Guiyun Tian, Mengchun Pan, Dixiang Chen, "Eddy current pulsed phase thermography and feature extraction," Appl. Phys. Lett., 103 (2013), 084104.

[15] A. Michel, B.J. Pease, M.R. Geiker, H. Stang, J.F. Olesen, "Monitoring reinforcement corrosion and corrosion-induced cracking using non-destructive x-ray attenuation measurements", Cement and Concrete Research, 41 (2011), 1085-1094. 